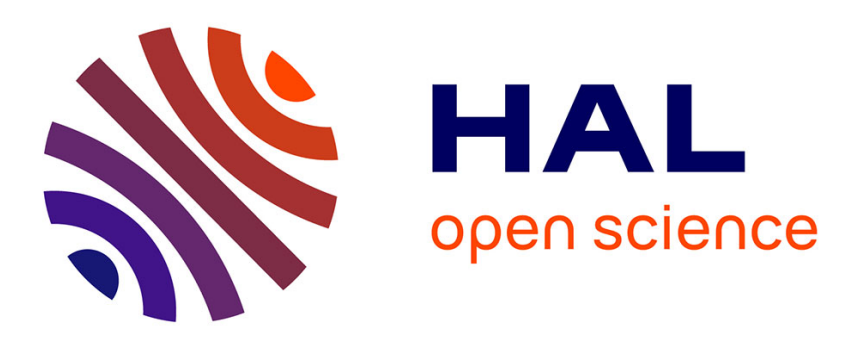

\title{
Titanium vanadium nitride electrode for micro-supercapacitors
}

\author{
A. Achour, R. Lucio-Porto, M. Chaker, A. Arman, A. Ahmadpourian, M.A. \\ Soussou, M. Boujtita, L. Le Brizoual, M.A. Djouadi, T. Brousse
}

\section{- To cite this version:}

A. Achour, R. Lucio-Porto, M. Chaker, A. Arman, A. Ahmadpourian, et al.. Titanium vanadium nitride electrode for micro-supercapacitors. Electrochemistry Communications, 2017, 77, pp.40-43. 10.1016/j.elecom.2017.02.011 . hal-01484528

HAL Id: hal-01484528

https://hal-univ-rennes1.archives-ouvertes.fr/hal-01484528

Submitted on 4 Jul 2017

HAL is a multi-disciplinary open access archive for the deposit and dissemination of scientific research documents, whether they are published or not. The documents may come from teaching and research institutions in France or abroad, or from public or private research centers.
L'archive ouverte pluridisciplinaire HAL, est destinée au dépôt et à la diffusion de documents scientifiques de niveau recherche, publiés ou non, émanant des établissements d'enseignement et de recherche français ou étrangers, des laboratoires publics ou privés. 


\title{
Titanium Vanadium Nitride Electrode For Micro-Supercapacitors
}

\author{
A. Achour ${ }^{1}$, R. Lucio-Porto, M. Chaker ${ }^{1}$, A. Arman $^{3}$, A. Ahmadpourian ${ }^{3}$,

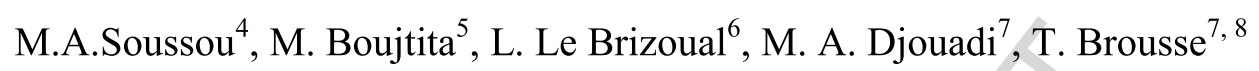 \\ ${ }^{1}$ Institut National de la Recherche Scientifique (INRS), 1650 Boulevard Lionel- Boulet, \\ Varennes, QC J3X 1P7. Canada \\ ${ }^{2}$ Universidad Autónoma de Nuevo León, Facultad de Ingeniería Mecánica y \\ Eléctrica, San Nicolás de los Garza, 66450, Nuevo León, México \\ ${ }^{3}$ Department of Physics, Kermanshah Branch, Islamic Azad University, \\ Kermanshah, Iran. \\ ${ }^{4}$ Laboratory of Thermal Processes, Research and Technology Center of Energy, Borj \\ Cedria Science and Technology Park, 2050 Hammam-Lif, Tunisia \\ ${ }^{5}$ CEISAM, Universite de Nantes, CNRS, 2 rue de la Houssiniere, BP 32229, 44322, \\ Nantes Cedex 3, France. \\ ${ }^{6}$ University of Rennes 1, Institut d'Electronique et de Télécommunications, IETR - \\ UMR CNRS 6164, Campus de Beaulieu -Bat 11D 263 Av General Leclerc 35042, \\ Rennes cedex, France. \\ ${ }^{7}$ Institut des Materiaux Jean Rouxel (IMN), Universite de Nantes, CNRS, 2 rue de la \\ Houssiniere, BP32229, 44322, Nantes Cedex 3, France \\ ${ }^{8}$ Reseau sur le Stockage Electrochimique de l'Energie (RS2E), FR CNRS, 3459, \\ France
}




\section{ABSTRACT}

Here we report on the synthesis of binary transition metal nitride electrodes based on titanium vanadium nitride (TiVN) thin films. These films were deposited by a method compatible with micro-electronic processes which consists of DC co-sputtering of vanadium (V) and titanium (Ti) targets. TiVN films with different $\mathrm{Ti} / \mathrm{V}$ ratio were deposited. A dependence of the capacitance and the cycling stability with the Ti/V atomic ratio in the films was established. While V rich sample exhibits a Faradic behavior that limits its cycling ability despite a high areal and volumetric capacity, the addition of Ti in the film drastically improves the cycling ability with virtually no fade in capacitance after 10000 cycles. Furthermore, a $1.1 \mathrm{Ti} / \mathrm{V}$ ratio leads to an areal capacitance up to 15 $\mathrm{mF} . \mathrm{cm}^{-2}$ in $1 \mathrm{M} \mathrm{KOH}$ electrolyte solution. Such electrodes shed light on the use of binary transition metal nitrides as candidate electrodes for micro-supercapacitor.

Keywords; Micro-supercapacitors, Transition metal nitride, Titanium nitride, Vanadium nitride 


\section{Introduction}

Electrochemical capacitors (ECs), also named supercapacitors, are energy storage devices that are being developed to fulfill the increasing energy demand of modern technologies and to complement other energy storage systems such as batteries [1-5]. Recently, transition metal nitrides (TMNs) such as RuN [6], VN [7-11], TiN [12-14], or $\mathrm{Mo}_{\mathrm{x}} \mathrm{N}$ $[14,15]$ have emerged as promising electrode materials for electrochemical capacitors. These materials are relatively inexpensive when deposited as thin films, they feature good chemical resistance, and most importantly, in contrast to oxides, they exhibit a very high electronic conductivity. Among these nanostructured TMNs, VN has shown impressive gravimetric capacitance up to $1340 \mathrm{~F} \mathrm{~g}^{-1}$ [7]. However, such high value seems to be due to faradaic reactions that strongly limits the cycling ability of vanadium nitride electrodes. Unlike VN, the electrochemical behavior of $\operatorname{TiN}[12,13]$ seems to be mainly ruled by capacitive charge storage which confers to the thin film electrodes quite a high cycling ability. In this study, we aim at coupling titanium and vanadium in binary TMNs, in order to emphasize the role of both elements for micro-supercapacitor applications.

In this work, we present for the first time results on the synthesis and electrochemical storage properties of TiVN thin films deposited by co-sputtering and investigated in aqueous $\mathrm{KOH}$ electrolyte. Many researchers are focusing on improving the gravimetric performance of the electrodes of ECs, but for portable electronics and micro-devices, the surface is the most important, especially when the electrodes are in the form of dense 
films [16-18]. This allow a direct integration of micro-supercapacitor at micro-scale level in order to bring portability.

In this work, we propose to emphasize the use of binary transition metal nitrides, namely $(\mathrm{Ti}, \mathrm{V}) \mathrm{N}$, for micro-supercapacitor applications, which couples the high cycling ability of TiN thin film electrode with the high areal capacitance of VN. Indeed, the capacitance and cycling stability of the TiVN thin film electrodes were found to be strongly dependent on $\mathrm{Ti} / \mathrm{V}$ ratio. We demonstrate an areal capacitance value of the TiVN electrode (with a Ti/V ratio close to 1.1 ) of $15 \mathrm{mF} . \mathrm{cm}^{-2}$ at $2 \mathrm{mV}^{-1}{ }^{-1}$ (corresponding to a volumetric capacitance of $500 \mathrm{~F} . \mathrm{cm}^{-3}$ ) with remarkable capacitance retention of more than $99 \%$ after 10000 cycles.

\section{Experimental Procedure}

\subsection{Deposition of the TiVN electrodes}

Titanium vanadium nitride (TiVN) films were deposited directly on (001) oriented silicon substrates by reactive DC Magnetron Co-Sputtering of vanadium and titanium targets in a sputter machine described in Ref [13]. Vanadium and titanium metal targets were used (purity 99.9\%). The reactive sputtering was carried out without substrate heating. The nitrogen and argon flux were kept constant at 2 and $19 \mathrm{sccm}$, respectively. The deposition time was fixed to 30 minutes at constant pressure of $2 \times 10^{-3}$ mbar. The applied power on the targets were changed in order to obtain films with different $\mathrm{Ti} / \mathrm{V}$ ratio. TiVN1 was deposited with an applied power of 90 watts on both Ti and V targets. TiVN2 was deposited with applied powers of 30 and 90 watts on $\mathrm{Ti}$ and $\mathrm{V}$ targets, respectively. Finally, TiVN3 was prepared with applied powers of 90 and 30 watts on Ti and $\mathrm{V}$ targets, respectively. 


\subsection{Structural and surface characterizations}

The samples were characterized by Scanning Electron Microscopy (SEM) performed on a JEOL JSM 7600F apparatus. X-ray diffraction (XRD) was performed on Siemens D5000 diffractometer using CuK $\alpha 1$ radiation in Bragg Brentano configuration. For surface analysis, XPS measurements were carried out on a Kratos Axis Ultra using AlKa $(1486.6 \mathrm{eV})$ radiation. High resolution spectra were acquired at $20 \mathrm{eV}$ pass energy with energy resolution of $0.9 \mathrm{eV}$.

\subsection{Electrochemical measurements}

Electrochemical measurements were performed in $1 \mathrm{M}$ potassium hydroxide $(\mathrm{KOH})$ (Alfa Aesar 99.99\%) aqueous solution electrolyte. A conventional three-electrode cell was used for electrochemical characterization. Electrochemical measurements were controlled via a VMP 3 multi potentiostat/galvanostat (Biologic) monitored with EC-Lab software. A PTFE cell holder was used to limit the surface area of the working electrode. For cycling voltammetry experiments, ten cycles were performed prior to those provided in the manuscript in order to assume that the cycles were reproducible. Long term cycling experiments were conducted at a temperature of $27^{\circ} \mathrm{C}$.

\section{Results and discussion}

Surface micro-structures of TiVN electrodes are displayed in SEM images (Fig.1a to 1c). It can be noticed that all the films show the same pyramidal shaped grains. This nanostructured morphology is similar to that obtained in the case of TiN films we have recently reported [13]. The grain size of the TiVN1 film ranges from 20 to $50 \mathrm{~nm}$, while the crystallites of TiVN2 and TiVN3 films are slightly lower $(10-40 \mathrm{~nm})$. The thicknesses 
of the electrodes are in the same order of magnitude as depicted from the cross section SEM images shown in Fig.1d (270, 240 and $220 \mathrm{~nm}$ for TiVN1, TiVN2 and TiVN3 films, respectively). The XRD patterns as shown in Fig.1e reveal that the three films are textured along (111) direction. The TiVN3 film shows a single phase and a preferential orientation according to the peak located at $36.9^{\circ}$ which is very close to the (111) diffraction peak of TiN $[13,19]$, with no peak related to VN. This similarity to TiN crystalline structure can be explained by the Ti/V ratio measured by XPS (Fig. 1f) which exhibits a larger amount of titanium compared to vanadium $(\mathrm{Ti} / \mathrm{V} \approx 1.8)$. As this ratio decreases, i.e. as the thin film incorporates more vanadium, this (111) peak shifts toward higher $2 \theta$ diffraction angles. Indeed, for a Ti/V ratio close to 0.7 (Fig. 1f), the (111) diffraction peak of TiVN2 film is located at $37.6^{\circ}$ which is close to the (111) peak of VN [20], and there is no peak assigned to TiN which also evidences a single phase for TiVN2 film. For intermediate composition $(\mathrm{Ti} / \mathrm{V} \approx 1.1), \mathrm{TiVN} 1$ film exhibits a preferential (111) orientation (at $37.2^{\circ}$ ) which is in-between the (111) peak of TiN and the (111) peak of VN. This peak can be assigned to a $(\mathrm{Ti}, \mathrm{V}) \mathrm{N}$ solid solution $[21,22]$. Thus it is expected that the electrochemical behavior of TiVN3 will be close to that of TiN and that of TiVN2 will look like that of VN thin film electrodes. An intermediate behavior is expected for TiVN1 sample.

Figure. 2 (a-f) show typical cycling voltammograms (CV) of TiVN electrodes measured in $1 \mathrm{M} \mathrm{KOH}$ electrolyte at different scan rates. The TiVN1 (Fig 2a-2b), TiVN2 (Fig 2c2d) and TiVN3 (Fig 2e-2f) were cycled in potential windows of [-0.9 -0.1$],[-1.3-0]$ and [-0.6-0.3], respectively, which present the safe electrochemical stability windows of each electrode [7-13]. At moderate scan rates, the CV curves corresponding to TiVN1 (Fig.2a) 
and TiVN3 (Fig.2e) electrodes exhibit a nearly rectangular shape in $1 \mathrm{KOH}$ electrolyte solution, indicative of a capacitive-like behavior. Furthermore, the CVs retain their rectangular shape even at higher scan rate (up to $500 \mathrm{mV} \cdot \mathrm{s}^{-1}$ ). The $\mathrm{CV}$ plots of TiVN2 electrode are quite different compared to those of the two other electrodes. Indeed, welldefined redox peaks can be depicted at $-0.8,-0.5,-1.1$ and $-0.7 \mathrm{~V}$. These peaks (which are highlighted at lower scan rate) originate from the faradaic behavior of $\mathrm{VN}$ involving protons in confined vanadium oxide/oxynitride that forms at the $\mathrm{VN}$ surface, as proposed by Choi et al [7]. However, this reaction mechanism has not been clearly evidenced up to now. It is worth mentioning that the electrochemical window of TiVN2 looks like that of $\mathrm{VN}$ in $\mathrm{KOH}$ electrolyte [5] and the electrochemical window of TiVN3 resembles that obtained for TiN in $\mathrm{KOH}$ electrolyte as previously reported by our group [5]. In Ref [5], we showed that the charge storage mechanism of TiN was mainly due to the double-layer capacitance of this material while for VN it was a mixture of capacitive (or pseudocapacitive) behavior and faradaic behavior. In the latter case, the faradaic behavior seems to improve the capacity of the electrode but it is detrimental to its cycling ability. In the present work, the electrochemical behavior for TiVN2 and TiVN3 electrodes shown in Figure $2 \mathrm{c}-\mathrm{d}$ and $2 \mathrm{e}-\mathrm{f}$ also looks like the electrochemical behavior of $\mathrm{VN}$ and a TiN phases, respectively, in good agreement with XRD patterns (Fig.1e). In the case of TiVN1 the CVs are similar to those of TiVN3, but with much higher capacitance. Since the thickness of both films are very close, this suggests that the electrochemical behavior of the binary titanium vanadium nitride possibly involves double layer capacitance and pseudo-capacitance when the $\mathrm{Ti} / \mathrm{V}$ atomic ratio is close to 1 . 
The areal capacitances of the different TiVN films versus scan rate are presented in Figure 3a. Since the film thicknesses is nearly the same for all the samples, a comparison of the areal capacitance is possible. The capacitance rapidly decreases for all the films when scan rates is increased from $2 \mathrm{mV} \cdot \mathrm{s}^{-1}$ up to $50 \mathrm{mV} \cdot \mathrm{s}^{-1}$. Then it stabilizes between 50 $\mathrm{mV} . \mathrm{s}^{-1}$ and $500 \mathrm{mV} \cdot \mathrm{s}^{-1}$. The highest capacitance is obtained for TiVN2 film with the highest V content (Fig.2a) mainly due to the Faradaic reactions related to the large amount of vanadium in this film $\left(24 \mathrm{mF} . \mathrm{cm}^{-2}\right.$ at $\left.2 \mathrm{mV}^{-1}{ }^{-1}\right)$. According to the capacitive behavior of TiN, TiVN3 films which has the highest $\mathrm{Ti} / \mathrm{V}$ ratio shows a limited capacitance of $5 \mathrm{mF} \cdot \mathrm{cm}^{-2}$ at $2 \mathrm{mV} \cdot \mathrm{s}^{-1}$. Despite a very similar electrochemical behavior, the intermediate composition sample TiVN1 exhibits a much higher capacitance than TiVN3, reaching $15 \mathrm{mF} \mathrm{cm}{ }^{-2}$ at $2 \mathrm{mV} \cdot \mathrm{s}^{-1}$. This behavior emphasizes the role of vanadium substitution in TiN films, improving the capacitance by a factor of 3 .

The long term cycling test of the vanadium rich sample TiVN2 (Fig.3b) at $100 \mathrm{mV} . \mathrm{s}^{-1}$, shows moderate cycling ability with $30 \%$ decay of the capacitance over 10.000 consecutive cycles. This fade in capacitance has been assigned to the presence of Faradaic reactions which probably irreversibly affects the structure and micro-structure of the film upon cycling. However, this has never been evidenced by in-situ analysis and some in-depth investigations are required in order to further highlight the charge storage mechanism and the changes occurring upon cycling VN electrodes. Unlike TiVN2 sample, TiVN1 and TiVN3 electrodes show an impressive cycling stability over 10.000 cycles with very low capacitance decay (less than $1 \%$ ). Such cycling ability is crucial for micro-supercapacitor application for long term use of the corresponding device. It is worth mentioning that the cycling ability of the TiVN electrodes decreases with the 
increase of vanadium content in the films. Indeed, the presence of more titanium in the film stabilizes the cycling efficiency. This was expected for a titanium rich TiVN film since TiVN3 exhibits a capacitive like behavior with a low areal capacitance $\left(1.5 \mathrm{mF} . \mathrm{cm}^{-}\right.$

${ }^{2}$ at $\left.100 \mathrm{mV} \cdot \mathrm{s}^{-1}\right)$. However, it is an unexpected improvement to keep such excellent cycling behavior together with improved capacitance $\left(6 \mathrm{mF} . \mathrm{cm}^{-2}\right.$ at the same scan rate). This is much higher than the areal capacitance reported for many $2 \mathrm{D}$ thin film electrodes designed with different materials reported in a recent review [16]. Furthermore, the cycling ability is quite impressive compared to existing literature in the field $[16,18]$. Many capacitance values are also reported as volumetric capacitance $[17,18,23]$. Despite the fact that this is not the right metric for comparison of thin film electrodes with different thicknesses, it can be noted that the volumetric capacitance of TiVN1 film reaches $500 \mathrm{~F} . \mathrm{cm}^{-3}$ at $2 \mathrm{mV} . \mathrm{s}^{-1}$ which compares well for example with carbide derived carbon thin films recently reported in the literature $\left(410 \mathrm{~F} . \mathrm{cm}^{-3}\right.$ at $\left.1 \mathrm{mV} \cdot \mathrm{s}^{-1}\right)$ [23].

\section{Conclusions}

TiVN films with different $\mathrm{Ti} / \mathrm{V}$ ratio were deposited on silicon for use as microsupercapacitor electrodes. It was found that the capacitance and cycling stability of the electrodes depend on the Ti/V ratio in the films. High vanadium content in the films lead to an increase of capacitance but at the expense of the cycling ability, while low vanadium content improves the cycling behavior but strongly decreases the areal capacitance. However, a film with a Ti/V ratio close to 1.1 exhibits both improved capacitance up to 15 $\mathrm{mF} . \mathrm{cm}^{-2}$ together with excellent cyclability over 10000 cycles. These performances are comparable to the state of art of the best electrodes reported in literature. Our results can 
open new perspectives to explore other binary/ ternary transition metal nitride electrode for electrochemical storage applications, where the role of the different metal cations need to be investigated. 


\section{References}

[1] P. Simon, Y. Gogotsi, Materials for electrochemical capacitors, Nature materials, 7 (2008) 845-854. doi:10.1038/nmat2297.

[2] M. Armand, J.M. Tarascon, Building better batteries, Nature, 451 (2008) 652-657. doi:10.1038/451652a.

[3] J.R. Miller, P. Simon, Electrochemical capacitors for energy management, Science Magazine, 321 (2008) 651-652. doi:10.1126/science.1158736.

[4] T.M. Dinh, A. Achour, S. Vizireanu, G. Dinescu, L. Nistor, K. Armstrong, D. Guay, D. Pech, Hydrous RuO 2/carbon nanowalls hierarchical structures for all-solid-state ultrahigh$\begin{array}{lllll}\text { energy-density micro-supercapacitors, Nano Energy, } 10 & \text { 288-294. }\end{array}$ doi:10.1016/j.nanoen.2014.10.003.

[5] R. Lucio-Porto, R Frappier, J.B Ducros, C. Aucher, H. Mosqueda, Sébastien Chenu, B. Chavillon, F. Tessier, F. Cheviré, T. Brousse, Titanium and vanadium oxynitride powders as pseudo-capacitive materials for electrochemical capacitors, Electrochimica Acta, 82 (2012) 257-262 . doi.org/10.1016/j.electacta.2012.05.032.

[6] S. Bouhtiyya, R.L. Porto, B. Laïk, P. Boulet, F. Capon, J.P. Pereira-Ramos, T. Brousse, J.F. Pierson, Application of sputtered ruthenium nitride thin films as electrode material for energy-storage devices, $\quad$ Scripta $\quad$ Materialia, $68 \quad$ (2013) 659-662. doi:10.1016/j.scriptamat.2013.01.030. 
[7] D. Choi, G.E. Blomgren, P.N. Kumta, Fast and Reversible Surface Redox Reaction in Nanocrystalline Vanadium Nitride Supercapacitors, Adv. Mater. 18 (2006) 1178-1182. 10.1002/adma.200502471.

[8] A. M. Glushenkov, D. Hulicova-jurcakova, D. Llewellyn, G. Q. Lu, and Y. Chen, Structure and capacitive properties of porous nanocrystalline VN prepared by temperatureprogrammed ammonia reduction of V2O5, Chem. Mater. 22 (2010) 914-921.

[9] A. Morel, Y. Borjon-Piron, R. Lucio Porto, T. Brousse, D. Bélanger, Suitable Conditions for the Use of Vanadium Nitride as an Electrode for Electrochemical Capacitor, Journal of The Electrochemical Society, 163 (2016) A1077-A1082.

[10] O. Bondarchuk, A. Morel, D. Bélanger, E. Goikolea, T. Brousse, R. Mysyk, Thin films of pure vanadium nitride: Evidence for anomalous non faradaic capacitance, Journal of Power Sources 324 (2016) 439-446.

[11] Y. Yan, B. Li, W. Guo, H. Pang, H. Xue, Vanadium based materials as electrode materials for high performance supercapacitors, Journal of Power Sources 329 (2016) 148169. doi: 10.1016/j.jpowsour.2016.08.039.

[12] A. Achour, J.B. Ducros, R.L. Porto, M. Boujtita, E. Gautron, L. Le Brizoual, M.A. Djouadi, T. Brousse, Hierarchical nanocomposite electrodes based on titanium nitride and carbon nanotubes for micro-supercapacitors, Nano Energy, 7 (2014) 104-113. doi:10.1016/j.nanoen.2014.04.008.

[13] A. Achour, R.L. Porto, M.-A. Soussou, M. Islam, M. Boujtita, K.A. Aissa, L. Le Brizoual, A. Djouadi, T. Brousse, Titanium nitride films for micro-supercapacitors: Effect of 
surface chemistry and film morphology on the capacitance, Journal of Power Sources, 300 (2015) 525-532. doi:10.1016/j.jpowsour.2015.09.012.

[14] Y.-J. Ting, K. Lian, N. Kherani, Fabrication of Titanium Nitride and Molybdenum Nitride for Supercapacitor Electrode Application, ECS Transactions, 35 (2011) 133-139. doi:10.1149/1.3655697.

[15] T.-C. Liu, W. G. Pell, and B. E. Conway, Behavior of molybdenum nitrides as materials for electrochemical capacitors comparison with ruthenium oxide, J. Electrochem. Soc., 145 (1998) 1882-1888.

[16] N.A. Kyeremateng, T. Brousse, D. Pech, Micro-supercapacitors as miniaturized energystorage components for on-chip electronics, Nat. Nanotechnol. (2016) DOI: 10.1038/nnano.2016.196.

[17] P. Huang, M. Heon, D. Pech, M. Brunet, P.-L. Taberna, Y. Gogotsi, S. Lofland, J.D. Hettinger, P. Simon, Micro-supercapacitors from carbide derived carbon (CDC) films on silicon chips, Journal of Power Sources, $225 \quad$ (2013) 240-244. doi:10.1016/j.jpowsour.2012.10.020.

[18] M. Beidaghi, Y. Gogotsi, Capacitive energy storage in micro-scale devices: recent advances in design and fabrication of micro-supercapacitors, Energy \& Environmental Science, 7 (2014) 867-884. doi:10.1039/c3ee43526a.

[19] J. Pelleg, L.Z. Zevin, S. Lungo, N. Croitoru, Reactive-sputter-deposited TiN films on glass substrates, Thin Solid Films, 197 (1991) 117-128. doi:10.1016/0040-6090(91)90225M. 
[20] Z.N. Dai, A. Miyashita, S. Yamamoto, K. Narumi, H. Naramoto, Crystalline and nearly stoichiometric vanadium nitride thin film by PLD, Thin Solid Films, 347 (1999) 117-120. doi:10.1016/S0040-6090(98)01726-X.

[21] G. Cui, L. Gu, A. Thomas, L. Fu, P.A. van Aken, M. Antonietti, J. Maier, A Carbon/Titanium Vanadium Nitride Composite for Lithium Storage, ChemPhysChem, 11 (2010) 3219-3223. doi:10.1002/cphc.201000537.

[22] T. Deeleard, S. Chaiyakun, A. Pokaipisit, P. Limsuwan, Effects of Vanadium Content on Structure and Chemical State of TiVN Films Prepared by Reactive DC Magnetron CoSputtering, Materials Sciences and Applications, Vol.04No.09 (2013) 8 doi:10.4236/msa.2013.49068.

[23] P. Huang, C. Lethien, S. Pinaud, K. Brousse, R. Laloo, V. Turq, M. Respaud, A. Demortière, B. Daffos, P.L. Taberna, B. Chaudret, Y. Gogotsi, P. Simon, On-chip and freestanding elastic carbon films for micro-supercapacitors, Science, 351 (2016) 691-695. doi:10.1126/science.aad3345. 


\section{Figure Captions}

Fig.1 Top view SEM images of TiVN electrodes for (a) TiVN1, (b) TiVN2 and (c) TiVN3 (d) SEM cross section of the three samples, (e) XRD pattern of TiVN electrodes, (f) elemental atomic percentage of Ti and V probed from XPS analyses.

Fig.2 Cyclic voltamograms curves versus scan rate of (a-b) TiVN1, (b-c) TiVN2, (c-d) TiVN3 electrodes.

Fig.3 (a) Areal capacitance versus scan rate of TiVN electrodes, (b) Capacitance retention of the electrodes at scan rate of $100 \mathrm{mV} \cdot \mathrm{s}^{-1}$ 


\section{ACCEPTED MANUSCRIPT}

Fig.1
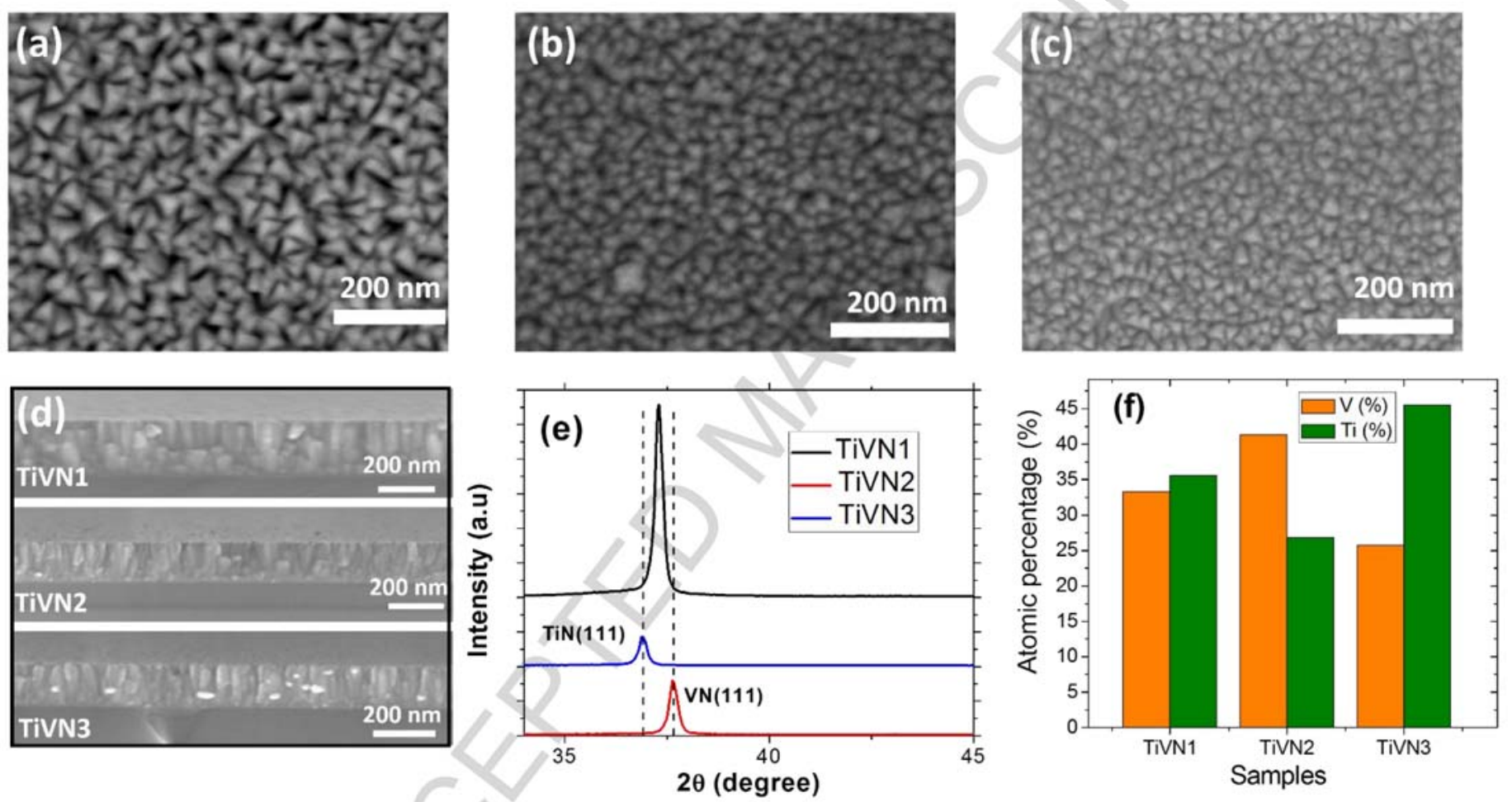

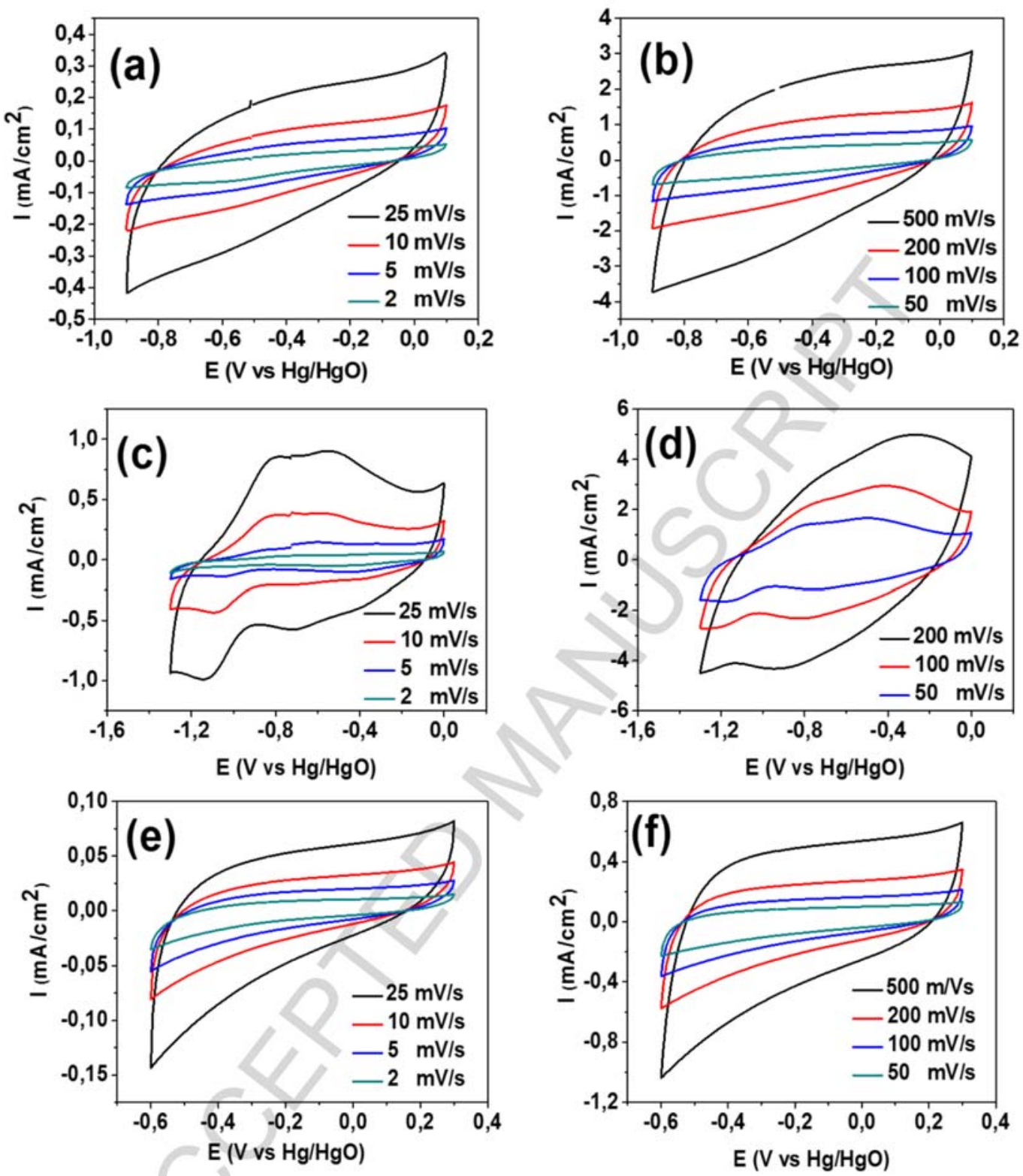

Fig.2 

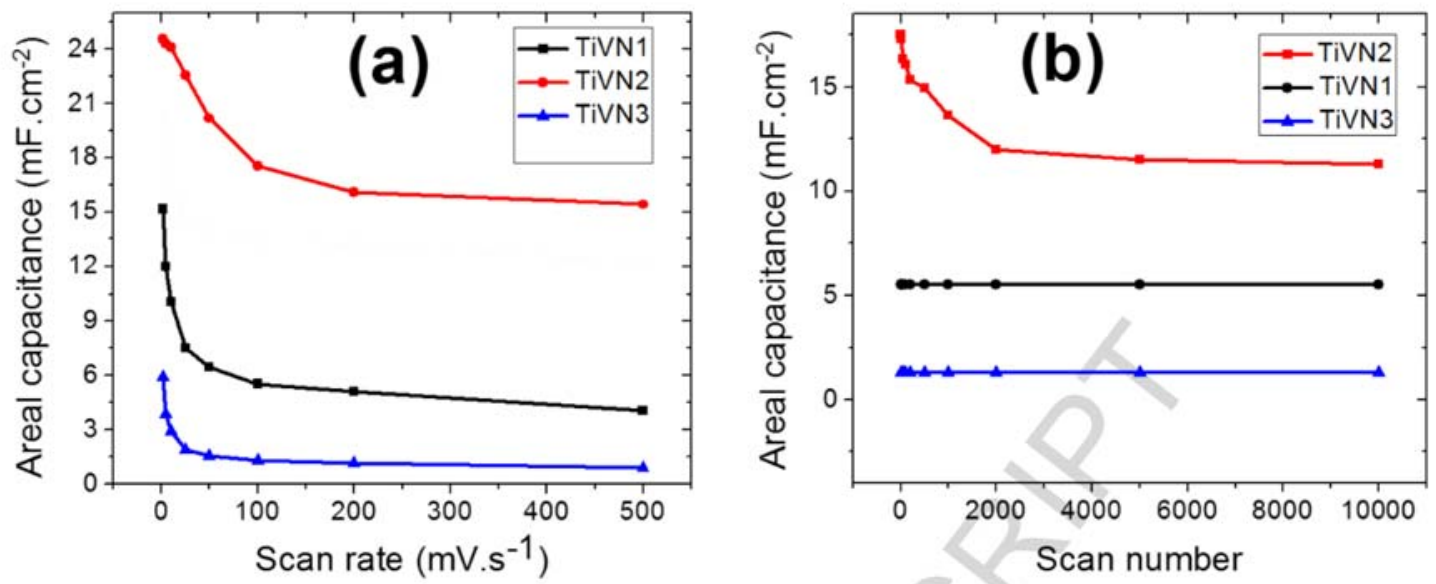

Fig.3 


\section{Highlights}

- TiVN electorchemical storage is reported for the first time

- Effect of Ti/V ratio on the electrode performances is demonstrated

- Enhancement of capacitance by factor of three without scarifying the cycling life

- Capacitance of $500 \mathrm{~F} . \mathrm{cm}^{-3}\left(15 \mathrm{mF} . \mathrm{cm}^{-2}\right)$ with no loss after 10000 cycles 